Volume 13

Number 2014

Article 3

October 2014

\title{
End of Life Ethics: Hospice and Advance Directives
}

Thomas Kehr

Cedarville University, tkehr@cedarville.edu

DigitalCommons@Cedarville provides a publication platform for fully open access journals, which means that all articles are available on the Internet to all users immediately upon publication. However, the opinions and sentiments expressed by the authors of articles published in our journals do not necessarily indicate the endorsement or reflect the views of DigitalCommons@Cedarville, the Centennial Library, or Cedarville University and its employees. The authors are solely responsible for the content of their work. Please address questions to dc@cedarville.edu.

\section{Recommended Citation}

Kehr, Thomas (2014) "End of Life Ethics: Hospice and Advance Directives," CedarEthics: A Journal of Critical Thinking in Bioethics: Vol. 13 : No. 2 , Article 3. 


\title{
End of Life Ethics: Hospice and Advance Directives
}

Browse the contents of this issue of CedarEthics: A Journal of Critical Thinking in Bioethics.

\begin{abstract}
It has been said, "Everybody will die, but very few people want to be reminded of that fact" (Handler, 2000, p.28). Perhaps this is the reason so few adults have advanced directives. Even after the 2005 public debate over the Terry Schiavo case, it has been calculated that two-thirds of Americans adults have not completed advance directives (Morhaim \& Pollack, 2013).

Americans are united in desiring that their wishes be honored. Sister Nancy, a senior Catholic Nun, had completed her living will. After a medical episode and hospitalization she was furious that hospital emergency physicians had not honored her advanced directives. Yes, her life was saved; but the sacred trust of patient and physician was broken. It is this sacred trust we all count on.

This paper will provide an ethical overview of advance directives, hospital care, hospice services, and physician roles and essential responsibilities. It will include socially responsible parameters for patient autonomy.

Finally, it will affirm biblical influence and advocacy in maintaining ethical care at the end of life.
\end{abstract}

\section{Keywords}

End of life, ethics, hospice, advance directives

\section{Creative Commons License} (c) 1 (1) $(9)$

This work is licensed under a Creative Commons Attribution-Noncommercial-No Derivative Works 4.0 License.

Follow this and additional works at: http://digitalcommons.cedarville.edu/cedarethics

Part of the Bioethics and Medical Ethics Commons 


\title{
End of Life Ethics: Hospice and Advance Directives
}

\author{
Thomas Kehr \\ Cedarville University
}

$I^{\prime}$ t has been said, "Everybody will die, but very few people want to be reminded of that fact" (Handler, 2000, p.28). Perhaps this is the reason so few adults have advanced directives. Even after the 2005 public debate over the Terry Schiavo case, it has been calculated that two-thirds of Americans adults have not completed advance directives (Morhaim \& Pollack, 2013).

Americans are united in desiring that their wishes be honored. Sister Nancy, a senior Catholic Nun, had completed her living will. After a medical episode and hospitalization she was furious that hospital emergency physicians had not honored her advanced directives. Yes, her life was saved; but the sacred trust of patient and physician was broken. It is this sacred trust we all count on.

This paper will provide an ethical overview of advance directives, hospital care, hospice services, and physician roles and essential responsibilities. It will include socially responsible parameters for patient autonomy. Finally, it will affirm biblical influence and advocacy in maintaining ethical care at the end of life.

\section{Advance Directives}

Autonomy is a celebrated God-given right. Our options must be preserved at the end of life. We must not yield our choices to others: family members, medical providers, facilities, insurers or politicians. It is our life, our values, and our goals that must be honored.

Written directives are not always sufficient. Sadly, there are times when a patient's advance directives have not been given to the medical provider. The clinician must act based on the information in the patient record. At other times, the medical scenario is more complicated than the language of the directive. In these cases, a healthcare power of attorney will insure that patient wishes are honored.

Patient rights, end-of-life planning, and advocacy are routine concerns for hospice chaplains. Patient wishes define the care-plans, especially for people with a limited lifespan. Potential conflicts between providers, patients, and family members must be resolved through ethical principles.

According to Porche (2012), the principles of beneficence, nonmaleficence, and autonomy guide our moral conduct. Beneficence is to do good for the patient whenever possible (Rae, 2009). Nonmaleficence guards a patient from harm done by a practitioner. Self-determined life closure is the expression of patient autonomy in hospice care. Individuals are afforded the rights to make informed decisions without coercion and persuasion. 
The development of medical technology, treatment options, specific disciplines and institutional goals have increased treatment options and have made decision-making more complicated for patients and families. Trusted clinicians (oncologists, osteopaths, therapists, nurses, and family physicians), social workers and family members each have their unique perspective as the illness progresses.

Each discipline has expected outcomes, which may vary according to their roles (Baggs et al., 2007). In some instances, hospice clinicians and family members are at odds. Family members occasionally refuse administration of as-needed (prn) pain medications and the patient has increased suffering at end-of-life. The family members can make these choices in hopes of having one last conversation with a non-responsive patient. In other cases, family members fear (for various reasons) administering the heavy doses of opioids required for hospice pain management. Education and re-assessment of patient wishes are essential.

Within families and healthcare providers, there exists a broad understanding of extreme measures. As research and discovery expands our hope for treatments and cures, some physicians and family members can redefine heroic treatment to a level far from a patient's intended choice. Physicians and family members can assume opposite ends of the spectrum. A doctor may push for an outcome, giving strong words to the family to accept a treatment plan.

A family can refuse to accept a prognosis, insisting on "doing everything" for their loved one. Sometimes personal faith and belief in the miraculous is a factor. Chaplains can assist in the dialogue affirming both the faith of the family and the validity of the clinical assessment.

These scenarios underscore the significance of advance planning. Many people will benefit from thorough conversation with their nurse or physician, and from time to reflect on their wishes. Patients should discuss their choices with their doctor and their family in order to expect that their intentions will be understood and honored.

\section{Five Wishes}

Five Wishes, a guide developed by The Robert Wood Foundation, provides detailed information for making individualized, case/person specific guidelines, leaving no gray areas for the reader of the document (Five Wishes, 2014). Though first prepared as a booklet, Five Wishes is now available online, complete with videos to clarify sections of the document. Upon completion, this personalized document immediately goes into effect in the District of Columbia and forty-two states. Efforts are underway to expand the use of this document across each of the states in the US. The document is highly helpful when having the end-of-life conversation with a patient in order to obtain their true desires on many different case scenarios.

The Five Wishes are as follows: 1) "The person I want to make health care decisions for me when I can't make them for myself." These pages provide a list of items to consider or cross out limiting the choices of the health care agent. In addition to life sustaining treatment, some items to consider include relocation of the patient to another state, admission to an extended care facility, and organ donation. 2) "My wish for the kind of medical treatment I want or don't want." Individuals list the types of "life support treatment" they wish to receive or decline, 
including detailing their observation of any religious and personal beliefs. This section discusses "close to death," comas, and brain damage. It should be noted that Five Wishes uses the language of "die within a short period of time" regarding life support treatment; it would be advisable for individuals to define this time frame for themselves. 3) "My wish for how comfortable I want to be." This section directly addresses the occasional trade-off between pain management and consciousness. This would minimize the ethical conflict expressed earlier where a family member refuses to allow the patient appropriate pain medication in hopes of having a final conversation. 4) "My wish for how I want people to treat me." Topics here include social, emotional, and spiritual matters including dignity and dying at home. 5) "My wish for what I want my loved ones to know." Values come through in this final wish - detailing matters of love, forgiveness, peace, reconciliation, grief recovery, and final preparations.

These wishes express much of what needs to be known by everyone involved in a patient's care. A thoughtful completion of these electronic or paper documents will provide a fairly comprehensive guide to avoid conflict and ethical dilemmas. However other resources may prompt additional considerations.

In his book, "Medical Care of the Soul," Dr. Bruce Bartlow explains how the "Pre-hospital DNR" refuses resuscitation by emergency workers. He goes on to describe a problem with this: "However it doesn't specify whether they should consider the reversibility of a problem in deciding whether to resuscitate, so you could die of an unanticipated, totally correctable problem." Bartlow may have a significant point, but perhaps his description of emergency workers (paramedics and emergency medical technicians) is presumptive. Their training to respond according to symptoms and code status may leave little room for "considering the reversibility of a problem." So once again we are left with our hopes set on an informed and reliable health care agent to intercede on our behalf.

\section{Emergency Department and Intensive Care}

More complex ethical dilemmas unfold in the emergency and intensive care environment. Medical advancements have increased public expectation and physician use of life-sustaining treatments. Disagreement can easily arise due to poor communication and conflicting goals. Hospital physicians observed that some families opt for life-extending treatment of critically ill patients, however brief, rather than experience an earlier death; meanwhile, family members may perceive that physicians are pressuring their medical decisions (Arnold, 2010).

Adding to these challenges is the reality that a patient's primary care provider usually ceases treatment upon hospital admission. At that time, a hospitalist (unknown to the patient and family and perhaps from a different cultural background) often becomes the physician. Conversations are often brief, and simply relate to lab values and the outcomes of procedures. Rarely do hospitalists ask, "What were your mother's / father's wishes?"

Perhaps an even greater concern lies in what never enters the discussion. Hospital outcomes may encourage transport from the surgery floor to the critical care unit, or from hospital admission to hospice admission. Patients and families may not be prepared for complex healthcare discussions or apprised of industry secrets. 


\section{Business Ethics and Contracts}

For example, many individuals are unaware that many of Dayton's hospital-based palliative care consultants (with hospital ID badges) are salaried by the local hospice to acquire admissions to their inpatient unit. Once the admission is complete, the hospice will keep the patient through the end of life. This practice has drawn the attention of extended care facilities, which lose residents and dollars in the process. It has also created a direct admission via the area hospitals to a singular hospice, denying or limiting patient choice and guaranteeing a dominant market share for the "community" hospice. Informed consent may exist as a legal signature sheet rather than a consistent reality.

Healthcare organizations should provide financial disclosures with consent forms and with fundraising literature. The public is largely unaware of contractual arrangements between physicians, facilities, rehabilitation, and hospice. Even for an industry insider, it is difficult to keep up with the latest mergers, acquisitions and financial incentives that skew healthcare conversations, and treatment plans. Though beneficence and nonmaleficence may be unaffected, autonomy is indirectly compromised by hidden business practices and compensation structures. Incentives from laboratories, pharmaceuticals, research projects, surgical procedures and bonuses (based on medical billing and inside referrals) could, in some manner, shape the presentation of treatment options.

\section{Medical Futility}

On the other hand, trusted medical professionals may offer the most balanced perspective. Some professionals fear that autonomy has given rise to "the ascendance of futility." According to King (1996), medical decision-making may become a tug-of-war, with patients setting goals according to their values and preferences, and physicians determining how and if treatments can accomplish those goals, based on their clinical knowledge and judgment. Most important in this discussion is the recognition that end-of-life decisions are not simply medical decisions. The process involves a patient's moral community, including people within and outside of the institution.

\section{Generational Differences}

Generational approaches to healthcare are dramatically different. Far from the compliant and trusting generation of their parents, baby boomers and younger generations are asking more questions and demanding more choices. Medical providers must provide complete information before expecting younger patients to sign consents. The technically proficient generations may research more about their health issues and likely overestimate their knowledge. Ethically, a patient must competently understand their choices. Some decisions are prior decisions made by patients, such as advance directives. Other decisions are "direct decisions made by the competent patient" (May, 2002). Often the advance directives are presented to the family members of a patient as a physician informs and involves family. This is often the case in hospice. 


\section{Patient Advocacy through Hospice}

Advocacy becomes a key principle in end-of-life to ensure that autonomy and advanced care planning are maintained when patients are no longer able to speak for themselves. Dame Cicely Saunders, founder of the hospice movement, expressed her experience as a physician caring for hospice patients. Saunders describes a patient's anguish of yearning to be heard:

Who is there in all the world who listens to us? Here I am, this is me, in my nakedness with my wounds, my secret grief, my despair, my betrayal, my pain which I can't express, my terror, my abandonment. Oh, listen to me for a day, an hour, a moment, lest I expire in my terrible wilderness, my lonely silence. Oh God, is there no one to listen? (Saunders, 1988, p. 31)

Thanks to Dame Saunders, people have listened. Hospice has changed dramatically since 1967 when she founded Saint Christopher's Hospice in London (Saint Christopher's Hospice, 2014). In 1978, Rev. Hugh Westbrook and Registered Nurse Esther Colliflower founded VITAS Innovative Hospice Care, my employer (VITAS, 2014). Westbrook and Colliflower had been listening to Saunders, Kubler-Ross, and patients desiring a death with dignity. Westbrook campaigned for Congress to pass laws providing for the reimbursement of hospice care (NHPCO, 2007). In 1981, Ronald Reagan signed into law the hospice Medicare benefit (Caring Foundations, 2012). With the advent of reimbursement, hospices have flourished. Not-for-profit and for-profit hospices have battled for market share. Hospices have educated the public; as a result people have thought more deliberately about their end-of-life choices. But do they have enough information?

Recently healthcare economics have changed. It will be interesting to see how hospitals and hospices handle changes in reimbursement. How will patients and family members fare? How will patient autonomy be honored? Will patients continue to have the choice to sign onto hospice care with the status of "Full Code?" How will the industry change, now that hospices must cover the costs of all of a patient's medications, not just those related to the primary diagnosis? Will more hospices selectively admit patients based on the costs of their medications and treatments? More precisely, will all of the public have access to hospice care? These are all ethical questions that call for patient advocacy.

\section{Biblical Ethics}

Our ethical foundations began with Scripture. Jesus preached, "Do to others as you would have them do to you" (Luke 6:31 - NIV. A hospice administrator warned against a literalist translation of the Golden Rule. She said, "Do to others as they would have you do to them." The point is clear: one should listen for and honor the voices (and wishes) of those less able to speak for themselves. Saunders said it beautifully, "You matter because you are you, and you matter until the end of your life. We will do all we can not only to help you die peacefully, but also to live until you die" (1988, p. 32). Proverbs 31:8-9 (Amplified) guides our advocacy, "Open your mouth for those unable to speak for themselves, for the rights of all who are left desolate and defenseless." This is the calling for the moral community (King, 1996). 
Individuals would be wise to carefully select an informed and trusted friend or family member who can advocate on their behalf. The best combination of advance planning involves both a completed living will and a well-informed healthcare power of attorney. Sister Nancy, the Catholic nun mentioned at the start of this paper, had completed a living will, yet her wishes had not been observed. She needed a trusted friend to carry out her wishes.

Dan Morhaim, a physician, observed "Though we Americans strive to control nearly every aspect of our lives, many of us abandon control of life's final passage" (2013, p. 8). Medical developments have made living will conversations more complex and the need for them more significant. Healthcare chaplains continually encourage people to face death with courage and to make informed and documented medical decisions for their future. They also assist families struggling with faith crises, grief, inner conflicts, and medical decisions. Chaplains intercede on behalf of an individual's religious and cultural convictions, building trust in the medical community.

\section{Conclusion}

When patients are unable to speak for themselves, others must serve as patient advocates, encouraging family, and providers to respect those sacred directives. As Christians, we must encourage the dying to make their peace with God, to set aside their fears of death, and to plan confidently for the future. Given healthcare's increasing complexity, they need an informed and confident spokesperson to speak on their behalf.

Biblical principles are essential for guiding end-of-life decisions. Christians must continue to influence our culture and community (patients, families, medical providers, insurers, lawyers and politicians). Christians must carefully seek God's wisdom in order to define ethical parameters. With so many choices regarding life and death, we have no option but to consult our Creator. The Spirit will guide us toward biblical wisdom in every scenario, so that we will respect the living and the dying.

\section{References}

Arnold, D., Burns, K., Choong, K., Cook, D., Cupido, C., Meade, M. (2010). A framework for resolving disagreement during end-of-life care in the critical care unit. Clinical and Investigative Medicine, 33(4), 240-253.

Baggs, J., Dombeck, M., Norton, S., Schmitt, M., Sellars, C., Quinn, J. (2007). Intensive care unit cultures and end-of-life decision making. Journal of Critical Care, 22(2), 159-168. doi: $\underline{10.1016 / j . j \mathrm{jcr} .2006 .09 .008}$

Bartlow, B. (2000). Medical care of the soul: A practical and healing guide to end-of-life for families, patients, and healthcare providers. Boulder, CO : Johnson Books.

Caring Foundations. (2012). Retrieved April 20, 2014, from www.caringfoundations.org 
Five wishes. Retrieved April 3, 2014, from www.agingwithdignity.org/fivewishes.php

Handler, D. (2000) The Austere Academy: A Series of Unfortunate Events. New York : HarperCollins Publishers.

International Association for Hospice \& Palliative Care. (2014). Retrieved April 11, 2014, from www.hospicecare.com/newsletter2004/april04/page7.html.

King, N. (1996). In: Clinical Medical Ethics. Washington, D.C.: Georgetown University Press.

Loewy, E., \& Loewy, R. (2002). The ethics of terminal care: orchestrating the end of life. New York : Kluwer Academic.

May, T. (2002). Bioethics in a liberal society: The political framework of bioethics decision making. Baltimore : Johns Hopkins University Press.

Morhaim, D., Pollack, K. (2013). A personal, economic, public policy and public health care crisis. American Journal of Public Health 103(6) 8-10. Retrieved from www.medscape.com/viewarticle/805452. doi: 10.2105/AJPH.2013.301316

National Hospice and Palliative Care Organization. (2007). Retrieved April 18, 2014, from www.nhpco.org/sites/default/files/public/newsline/2007/March07.pdf

Porche, D.J. (2012). Health policy: Application for nurses and other healthcare professionals. Jones \& Bartlett Learning.

Rae, S. (2009). Moral choices: An introduction to ethics. Grand Rapids: Zondervan.

Saint Christopher's Hospice. (2014). Retrieved April 12, 2014, from www.stchristophers.org.uk/about/history.

Saunders, C. Spiritual pain. (1988). Journal of Palliative Care. (4) pp. 29-32.

VITAS Hospice Care. (2014). Retrieved June 30, 2014, from http://www.vitas.com/oh/cincinnati-dayton-hospice. 